\title{
WHAT MAKES MULTINATIONAL CLINICAL RESEARCH ETHICAL \& HOW TO MINIMIZE POSSIBLE EXPLOITATION IN HOST COUNTRY?
}

\author{
Dr. Md. Ashraf Ali \\ Former consultant, Health \& Population Sector Program of Bangladesh, DFID, British Council, Dhaka
}

BACKGROUND: In recent years there has been substantial debate about the ethics of research in developing countries. The controversies have been centered on (i) standard of care that should be used in research (ii) reasonable availability of interventions that are proven to be useful and (iii) quality of informed consent. Clinical research is different from clinical practice in ethically important ways where each has different goals, different methods and different justification for risk to individuals. The goal of clinical research is to generate useful knowledge about health and illness. Benefit to participants is not the purpose of research, although it does occur. Here people are the means to develop useful knowledge; and are thus at risk of exploitation.

POSSIBLE EXPLOITATION OF HOST COUNTRY: In developed countries, the risk of exploitation of human research subjects or host communities is minimized, because (i) society funds research to improve health (ii) researchers and research institutions are part of the larger community and (iii) there is an infrastructure, even if imperfect, translates research results into health-care practices for the benefit of the larger community. But multinational clinical research in developing countries creates a greater risk of exploitation due to (i) poverty, (ii) illiteracy, (iii) limited health care services, (iv) Cultural and linguistic differences and (v) less understanding of the nature of scientific research. Moreover regulatory infrastructures that might minimize the risk of exploitation are less established, less supported and less effective in developing countries. As a consequence, individuals or communities in developing countries assume the risk of research, but most of the benefits may accrue to people in developed countries.

HOW TO MINIMIZE EXPLOITATION: To minimize the possibility of exploitation, previously, there was delineation of a framework for ethical research that included 7 principles. Later on an $8^{\text {th }}$ principle 'collaborative partnership' was added and elaborated these principles through 31 benchmarks that systematically specify practical measures to determine the extent to which the research satisfies the principles. The principles are as follows:

Collaborative partnership: A collaborative partnership between researchers \& sponsors in developed countries \& researchers, policy makers \& communities in developing countries helps to minimize the possibility of exploitation by ensuring that a developing country determines for itself whether the research is acceptable \& responsive to the community's health problems. Moreover without the engagement of the researchers \& host communities in the developing country, a study is unlikely to have any lasting impact, and without the investment of makers of health policy, the research results are unlikely to influence policy making \& the allocation of scarce health care resources.

Social value: It is widely recognized that ethical clinical research must have social value, through generation of knowledge that can lead to improvement in health; without social value, research exposes participants to risks for no good reason \& wastes resources.

Scientific validity: Science \& ethics do not conflict; valid science is an ethical requirement. Unless research generates reliable \& valid data that can be interpreted \& used by the specified beneficiaries of the research, it will have no social value $\&$ participants will be exposed to risks for no benefits.

Fair subject selection: Historically, populations that were poor, uneducated, or powerless to defend their own interest were targeted for high risk research, whereas promising research was preferentially offered to more privileged individuals. A challenge for research in developing countries is fair selection of target villages, tribes or city neighborhoods from which individual participants will be recruited. 
The delineated ethical principles are elaborated through benchmarks which are as follows:

\begin{tabular}{|c|c|}
\hline Principles & enchmarks \\
\hline $\begin{array}{l}\text { Collaborative } \\
\text { partnership }\end{array}$ & 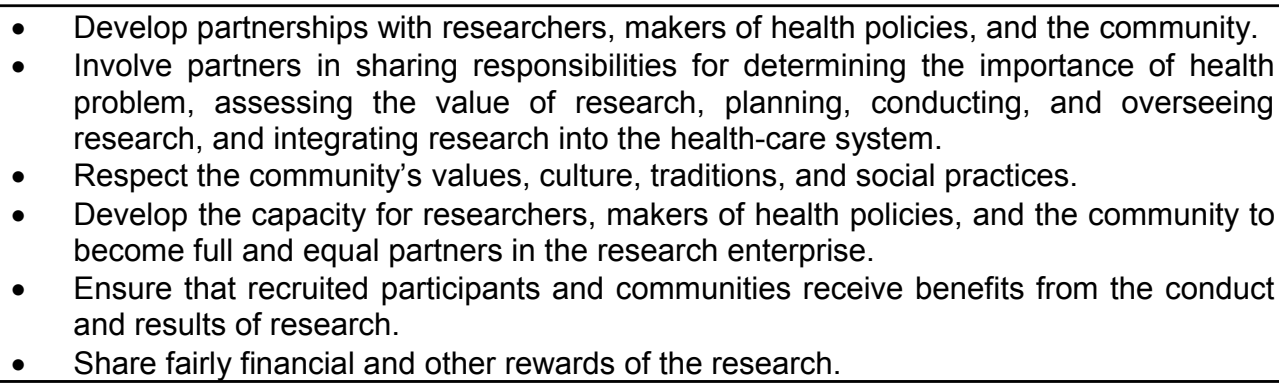 \\
\hline Social value & $\begin{array}{l}\text { - Specify the beneficiaries of the research-who. } \\
\text { - Assess the importance of the health problems being investigated and the prospective } \\
\text { value of the research for each of the beneficiaries-what. } \\
\text { - Enhance the value of the research for each of the beneficiaries through dissemination } \\
\text { of knowledge, product development, long-term research collaboration, and/or health } \\
\text { system improvements. } \\
\text { - Prevent supplanting the extant health system infrastructure and services. }\end{array}$ \\
\hline Scientific validity & $\begin{array}{l}\text { - Ensure that the scientific design of the research realizes social value for the primary } \\
\text { beneficiaries of the research. } \\
\text { Ensure that the scientific design realizes the scientific objectives while guaranteeing } \\
\text { research participants the health-care interventions to which they are entitled. } \\
\text { Ensure that the research study is feasible within the social, political, and cultural } \\
\text { context or with sustainable improvements in the local health-care and physical } \\
\text { infrastructure. }\end{array}$ \\
\hline $\begin{array}{l}\text { Fair selection of } \\
\text { study population }\end{array}$ & $\begin{array}{l}\text { - } \quad \text { Select the study population to ensure scientific validity of the research. } \\
\text { - Select the study population to minimize the risks of the research and enhance other } \\
\text { principles, especially collaborative partnership and social value. } \\
\text { - } \quad \text { Identify and protect vulnerable populations. }\end{array}$ \\
\hline $\begin{array}{l}\text { Favorable risk-benefit } \\
\text { ratio }\end{array}$ & $\begin{array}{l}\text { - Assess the potential risks and benefits of the research to the study population in the } \\
\text { context of its health risks. } \\
\text { Assess the risk-benefit ratio by comparing the net risks of the research project with the } \\
\text { potential benefits derived from collaborative partnership, social value, and respect for } \\
\text { study populations. }\end{array}$ \\
\hline Independent review & $\begin{array}{l}\text { - } \quad \text { Ensure public accountability through reviews mandated by laws and regulations. } \\
\text { - } \quad \text { Ensure public accountability through transparency and reviews by other international } \\
\text { and nongovernmental bodies, as appropriate. } \\
\text { - } \quad \text { Ensure independence and competence of the reviews. }\end{array}$ \\
\hline Informed consent & $\begin{array}{l}\text { - Involve the community in establishing recruitment procedures and incentives. } \\
\text { - } \quad \text { Disclose information in culturally and linguistically appropriate formats. } \\
\text { - } \quad \text { Implement supplementary community and familial consent procedures where culturally } \\
\text { appropriate. } \\
\text { - } \quad \text { Obtain consent in culturally and linguistically appropriate formats. } \\
\text { Ensure the freedom to refuse or withdraw. }\end{array}$ \\
\hline $\begin{array}{l}\text { Respect for recruited } \\
\text { participants and } \\
\text { study communities }\end{array}$ & $\begin{array}{l}\text { - } \quad \text { Develop and implement procedures to protect the confidentiality of recruited and } \\
\text { enrolled participants. } \\
\text { - } \quad \text { Ensure that participants know they can withdraw without penalty. } \\
\text { Provide enrolled participants with information that arises in the course of the research } \\
\text { study. } \\
\text { - Monitor and develop interventions for medical conditions, including research-related } \\
\text { injuries, for enrolled participants at least as good as existing local norms. } \\
\text { - Inform participants and the study community of the results of the research. }\end{array}$ \\
\hline
\end{tabular}

Favorable risk-benefit ratio: A clinical research should offer participants a favorable risk-benefit ratio, or, if potential risks outweigh benefits to participants, the social value must justify these risks. Only benefits that accrue to 
participants from the interventions necessary to achieve the research objectives or those deriving from the knowledge to be gained by the research should be used to justify risks to participants.

Independent review: To minimize concerns with regard to researchers' conflicts of interest \& to ensure public accountability, independent ethical review of all clinical research protocols is necessary. In multinational research, there is a special need for transparency. Transparency enhances accountability by assuring the public that the research is not exploitative.

Informed consent: Individual informed consent has been recognized as a principle of ethical clinical research for more than a century. The concept of formally taking consent with emphasis on patient's rights \& his/her autonomy emerged in early twentieth century when some law suits were filed in courts, particularly in USA. Later the well known infamous atrocities carried by Nazi doctors on prisoners during Second World War \& consequent verdict by Nuremberg tribunal \& milestone declaration of Nuremberg made a landmark in the history of medical ethics \& provide a ground on which the doctrine of informed consent is built.

Respect for recruited participants \& study communities: The ethical conduct of clinical research does not end when informed consent is obtained. Researchers have ongoing obligations to participants, former participants \& the host community.

DISCUSSION \& CONCLUSION: Together, these principles \& benchmarks constitute a systematic framework that specifies core practical considerations necessary to ethically justify research in developing countries. This framework functions within general ethical values, such as honesty, that are relevant to scientific integrity and avoidance of fraud. Application to actual research studies may suggest refinement or the need for additional benchmarks. For a developing country to minimize the risk of exploitation it is necessary to apply a previously proposed ethical framework for clinical research within developed countries to developing countries, explicating a previously implicit requirement for collaboration. Application of ethical framework of principles and benchmarks in designing and conducting clinical research is essential to minimize the risk of exploitation. To apply these ethical principles and benchmarks in clinical research the host country has to build capacity of its researchers and research institutions for (i) establishment of a system for independent ethical review of research proposals and (ii) development and implementation of standard operating procedures for both clinical research and ethics review.

\section{REFERENCES:}

1. Angell M. The ethics of clinical research in the Third World. N Engl J Med 1997; 337:847-9.

2. Wilmshurst $P$. Scientific imperialism: if they won't benefit from the findings, poor people in the developing world should not be used in research. BMJ 1997; 314:840-1.

3. Del Rio C. Is ethical research feasible in developed and developing countries? Bioethics 1998; 12:328-30.

4. Glantz LH, Annas GJ, Grodin MA, Mariner Wk. Research in developing countries: taking 'benefit' seriously. Hastings Cent Rep 1998; 28:38-42.

5. Angel M. Ethical imperialism? Ethics in international collaborative clinical research. N Engl J Med 1998; 319:1081-3.

6. Wertheimer A. Exploitation Princeton, NJ: Princeton University Press, 1999:3-15

7. Emanuel EJ, Wendler D, Grady C. What makes clinical research ethical? JAMA 2000; 283:2701-11

8. Stephens J. The body hunters: as drug testing spreads, profits and lives hang in balance. Washington Post, 17 December 2000:A 1.

9. Weijer C, Anderson JA. The ethics wars: disputes over international research. Hastings Cent Rep 2001; 31:1820.

10. Shapiro H, Meslin E. The ethics of international research. N Engl J Med 2001; 314:139-42.

11. Black N. Evidence based policy: proceed with care. BMJ 2001; 323:275-8. 
Bangladesh Journal of Bioethics 2011; 2(2): 20-23

12. Daniels N, Sabin JE. Setting limits fairly. In: Justice, security, and public accountability for limits. New York: Oxford University Press, 2002:13-14. 